\title{
Analysis of Codon Bias in Mitochondrial Genome of Epinephelus Fuscoguttatus
}

\section{Lirong Bai \\ Beibu Gulf University \\ Lili Lu \\ Beibu Gulf University \\ Suping Li \\ Beibu Gulf University \\ Jicui He \\ Beibu Gulf University \\ Jian Chen \\ Beibu Gulf University}

\section{Pei Wang}

Beibu Gulf University

\section{Yin Guo}

Beibu Gulf University

Hongchen Wang

Beibu Gulf University

Dahui Yu ( $\nabla$ pearlydh@163.com )

Beibu Gulf University

\section{Research Article}

Keywords: Epinephelus fuscoguttatus, Mitochondrial genome, Codon preference

Posted Date: June 11th, 2021

DOl: https://doi.org/10.21203/rs.3.rs-590314/v1

License: (c) (i) This work is licensed under a Creative Commons Attribution 4.0 International License.

Read Full License 


\section{Epinephelus fuscoguttatus}

3

Lirong Bai”, Lili Lü, Suping Li, Jicui He, Jian Chen, Pei Wang, Yin Guo, Hongchen Wang,

4

Dahui $\mathrm{Yu}^{1 *}$

5

Guangxi Key Laboratory of Beibu Gulf Marine Biodiversity Conservation, Beibu Gulf

6

University, Qinzhou 535011, Guangxi, PR China

7

Lirong Bai and Lili Lu contributed equally to this work.

8

Corresponding Author: Dahui Yu

9

10

11

12

13

14

15

16

17

18

19

20

21

22 


\section{Epinephelus fuscoguttatus}

25 Abstract

26 Background: Epinephelus fuscoguttatus is one of the rare marine economic fishes with high

27 economic value. At present, the researches on grouper mainly focus on artificial propagation,

28 physiology and biochemistry, diseases and so on. However, there are few reports on mitochondrial

29 genome level. The research aimed to analyze composition characteristics and usage preference of

30 codon of mitochondrial genome in E. fuscoguttatus, and explored main factors of affecting the

31 formation of codon preference, thereby providing theoretical basis for studying species evolution,

32 genetics and breeding, and improving expression efficiency of exogenous genes.

33 Results: GC content of mitochondrial genome of E. fuscoguttatus changed between $44.00 \%$ and

$3446.30 \%$, with $45.40 \%$ of mean. Change range of CAI value was between 0.125 and 0.202 , and the mean was 0.155 . Effective number of codons (ENC) changed between 36.08 and 49.55, with 44.98 of mean. There were 32 codons that relative synonymous codon usage (RSCU) was more than 1 , mainly ended with A/C. ENC-plot analysis found that all the genes were in the lower middle of the standard curve, and there was larger difference between actual and theoretical ENC, illustrating that codon bias was mainly affected by the choice. Correspondence analysis showed that the first axis contributed $58.85 \%$ of the difference, while the second, third and fourth axes contributed $14.59 \%$, $7.66 \%$ and $5.43 \%$ of the difference respectively. Cumulative contribution rate of the first four vectors was $85.53 \%$. Finally, nine optimal codons were selected: CUU, AUC, GUU, CCU, GCA, UAU, CGC, AGC and GGC.

Conclusions: Codon usage preference of mitochondrial genome of E. fuscoguttatus was weak, and 
45 it preferred to use $\mathrm{A} / \mathrm{C}$ terminated codon, and preference was mainly influenced by choice.

46 Key words: Epinephelus fuscoguttatus, Mitochondrial genome, Codon preference

\section{Background}

49 According to the genetic central dogma, each triplet codon encodes and translates an amino acid in the polypeptide chain ${ }^{[1]}$. In eukaryotes, there are 61 triplet codons encoding 20 kinds of amino

51 acids and three stop codons (TAA, TAG, TGA). Except methionine and tryptophan have only one

52 codon, other 18 kinds of amino acids are encoded by 2-6 codons ${ }^{[2]}$. Among them, codons that encode

53 the same amino acid are called synonymous codons ${ }^{[3]}$. The frequency of synonymous codons is

54 different, which is called codon preference ${ }^{[4]}$. There are many factors influencing the formation of

55 codon usage preference, such as gene expression level, gene length, base composition, amino acid

56 conservation, protein hydrophilicity, transcriptional selection and RNA stability ${ }^{[5-7]}$. It is helpful to

57 provide a theoretical basis for analyzing its gene expression, high expression of foreign genes and

58 molecular evolution by studying codon preference of one species.

59 Mitochondria are important organelles in eukaryotic cells, which can provide a place for a series

60 of life activities of cells, such as cell information transmission, energy transformation, cell

61 differentiation and apoptosis ${ }^{[8]}$. Mitochondrial DNA is characterized by maternal inheritance, easy

62 amplification, high conservation and rapid evolution ${ }^{[9-10]}$. Therefore, mitochondrial genome is

63 widely used in genome evolution ${ }^{[11]}$, population genetics ${ }^{[12]}$, and systematic evolution ${ }^{[13]}$. In recent

64 years, the study on codon usage preference of mitochondrial genome has been successively reported

65 in many animals and plants, such as Oplegnathus punctatus and Oplegnathus fasciatus ${ }^{[14]}$, Aquarius

66 paludum $^{[15]}$, Eurydema dominulus ${ }^{[16]}$, Glycine max and Glycine soja ${ }^{[17]}$, Fusarium solani $^{[18]}$. 
68 Perciformers, Actinopterygii ${ }^{[19-20]}$, and is distributed in subtropical and tropical seas. It has the

69 characteristics of fast growth, large specifications, delicious taste and rich nutrition, and very high

70 economic value, and is one of the rare marine economic fishes ${ }^{[21]}$. At present, domestic and foreign

71 researches on E. fuscoguttatus mainly focus on artificial propagation, physiology and biochemistry,

72 diseases and so on. Liao Jingqiu et al. ${ }^{[22]}$ studied karyotype structure of chromosomes of $E$.

73 fuscoguttatus. Fan Yanjun et al. ${ }^{[23]}$ established cell lines of fin, heart and swim bladder of $E$.

74 fuscoguttatus. Shi Gang et al. ${ }^{[24]}$ studied tolerance of E. fuscoguttatus to gradual and abrupt changes

75 in salinity. Shapawi et al. ${ }^{[25]}$ studied how to optimize the growth performance of $E$. fuscoguttatus by

76 adjusting the fat and protein contents of feed. By sequencing and analyzing brain, liver and muscle

77 of E. fuscoguttatus, Lin Mingde ${ }^{[26]}$ obtained transcriptome data of brain, liver and muscle, and

78 screened some differentially expressed genes related to growth. Most of these studies start with

79 physiological diseases, but few studies are reported at the mitochondrial genome level. In this paper,

80 mitochondrial gene sequence of E. fuscoguttatus was taken as research object for analyzing codon

81 preference. The codon with high preference for the species was understood, and optimal codon was

82 determined, and the factors affecting its codon preference were explored, which could provide

83 scientific basis for studying germplasm resources, fish evolution, genetics and breeding.

\section{$84 \quad 2$ Results}

852.1 Analysis of codon composition

86 To more accurately analyze codon preference, nine non repetitive genes that took ATG as start

87 codon, and sequence length of coding region was more than $300 \mathrm{bp}$ in mitochondrial genome of $E$.

88 fuscoguttatus were selected, and software Codonw was used for analyzing codon usage preference. 
89 The results showed that GC contents on the first, second and third positions of codon changed

90 between $46.70 \%$ and $60.00 \%, 32.50 \%$ and $48.30 \%$, and $38.70 \%$ and $48.10 \%$ (Table 1 ), and their

91 means were $54.30 \%, 39.80 \%$, and $42.00 \%$. GC content in the second place was lower than that in

92 the third place, while GC content in the third place was also lower than that in the first place. ENC

93 value changed between 36.08 and 49.55 , with 44.98 of mean. Change range of CAI was between

940.125 and 0.202 , and the mean was 0.155 . Change range of CBI was between -0.066 and 0.043 , and

95 the mean was -0.011 . FOP changed between 0.327 and 0.422 , with 0.376 of mean. Gravy of protein

96 changed between -0.917 and 1.136 , and the mean was 0.685 .

Table 1 Major parameters of codon in mitochondrial genome of E. fuscoguttatus

\begin{tabular}{lllllllllllll}
\hline Gene & GC1 & GC2 & GC3 & GC & GC3S & ENC & CAI & CBI & FOP & Gravy \\
\hline ND1 & 0.554 & 0.410 & 0.401 & 0.456 & 0.394 & 40.36 & 0.134 & -0.059 & 0.343 & 0.882 \\
ND2 & 0.519 & 0.433 & 0.427 & 0.460 & 0.422 & 42.78 & 0.128 & -0.060 & 0.341 & 0.875 \\
COX1 & 0.548 & 0.396 & 0.426 & 0.457 & 0.414 & 47.08 & 0.202 & 0.020 & 0.412 & 0.901 \\
COX2 & 0.600 & 0.325 & 0.395 & 0.440 & 0.387 & 47.17 & 0.191 & 0.034 & 0.414 & 0.468 \\
ATP6 & 0.554 & 0.371 & 0.415 & 0.446 & 0.413 & 49.55 & 0.125 & -0.047 & 0.332 & 1.136 \\
ND3 & 0.576 & 0.387 & 0.387 & 0.450 & 0.382 & 36.08 & 0.125 & -0.066 & 0.327 & 1.046 \\
ND4 & 0.536 & 0.400 & 0.430 & 0.456 & 0.423 & 46.12 & 0.136 & 0.028 & 0.391 & 0.963 \\
ND5 & 0.467 & 0.483 & 0.420 & 0.457 & 0.401 & 48.84 & 0.172 & 0.006 & 0.403 & -0.917 \\
CYTB & 0.530 & 0.377 & 0.481 & 0.463 & 0.477 & 46.85 & 0.182 & 0.043 & 0.422 & 0.814 \\
Mean & 0.543 & 0.398 & 0.420 & 0.454 & 0.413 & 44.98 & 0.155 & -0.011 & 0.376 & 0.685 \\
\hline
\end{tabular}


101 correlation between GC2 and GC3, and GC3 was significantly correlated with GC, with 0.702 of

102 correlation coefficient. GC3 showed extremely significant correlation with GC3S, with 0.984 of

103 correlation coefficient, while there was no significant correlation between GC3S and CAI, CBI, Fop,

104 ENC, Gravy. ENC was related to $\mathrm{GC} 1, \mathrm{GC} 2, \mathrm{GC} 3$, but it did not reach significant level, illustrating

105 that base composition had an effect on codon bias, but it was not the main factor.

\begin{tabular}{|c|c|c|c|c|c|c|c|c|c|c|}
\hline Item & $\mathrm{GC1}$ & $\mathrm{GC} 2$ & GC3 & $\mathrm{GC}$ & GC3S & ENC & CAI & CBI & FOP & Gravy \\
\hline $\mathrm{GC} 2$ & $-0.900 * *$ & & & & & & & & & \\
\hline $\mathrm{GC} 3$ & -0.461 & 0.112 & & & & & & & & \\
\hline GC & $-0.686^{*}$ & 0.626 & $0.702 *$ & & & & & & & \\
\hline GC3S & -0.344 & -0.002 & $0.984 * *$ & 0.650 & & & & & & \\
\hline ENC & -0.328 & -0.020 & 0.442 & -0.067 & 0.375 & & & & & \\
\hline CAI & -0.013 & -0.177 & 0.319 & 0.027 & 0.216 & 0.506 & & & & \\
\hline CBI & -0.081 & -0.230 & 0.530 & 0.074 & 0.451 & 0.639 & $0.789 *$ & & & \\
\hline FOP & -0.712 & -0.100 & 0.513 & 0.163 & 0.408 & 0.407 & $0.900 * *$ & $0.965^{* *}$ & & \\
\hline Gravy & 0.645 & -0.593 & 0.006 & -0.080 & 0.161 & -0.367 & -0.383 & -0.293 & -0.293 & \\
\hline Aromo & -0.150 & 0.066 & 0.360 & 0.344 & 0.279 & 0.127 & 0.644 & 0.407 & 0.407 & -0.233 \\
\hline
\end{tabular}

107 Note: * means significant correlation at 0.05 level; ** means significant correlation at 0.01 level.

108 RSCU is an important parameter of measuring codon usage bias ${ }^{[29]}$. When RSCU value of codon

109 is equal to 1 , it shows that the codon has no preference. When RSCU value is more than 1 , it shows

110 that the codon is frequently used. When RSCU value is less than 1, it shows that the codon is less 
111 used ${ }^{[30]}$. RSCU analysis results showed that there were 32 codons that RSCU was more than 1 (Table

112 3). Among them, there were 15 codons ending in $C, 11$ codons ending in $A, 6$ codons ending in $U$,

113 and none ending in $\mathrm{G}$.

$114 \quad 2.2$ Neutral plot analysis

115 GC3 was taken as horizontal ordinate, and GC12 was used as vertical ordinate for correlation 116 analysis. If there was significant correlation between $\mathrm{GC} 12$ and $\mathrm{GC} 3$, it showed that the base

117 selection preferences of the three positions of codon were similar, and codon usage bias was affected

118 by mutation. If there was no significant correlation between GC12 and GC3, and regression 119 coefficient was close to 0 , it illustrated that codon usage bias was influenced by selection. Neutral 120 plot analysis of mitochondrial genes in E. fuscoguttatus was shown as Fig.1. In Fig.1, most of the

121 genes were located above the diagonal, and $\mathrm{GC} 12$ changed between $45.35 \%$ and $48.20 \%$, while

122 change range of GC3 was between $38.70 \%$ and $48.10 \%$, and the distribution range of both was small.

123 Correlation coefficient between GC12 and GC3 was - -0.648 , and regression coefficient (namely

124 slope in Fig.1) was 0.2257, which was close to 0. Bilateral test did not reach significant level

$125(P>0.05)$, showing that correlation between GC12 and GC3 was weaker. The results showed that 126 selection was main factor forming codon preference of mitochondrial genome in E. fuscoguttatus. 


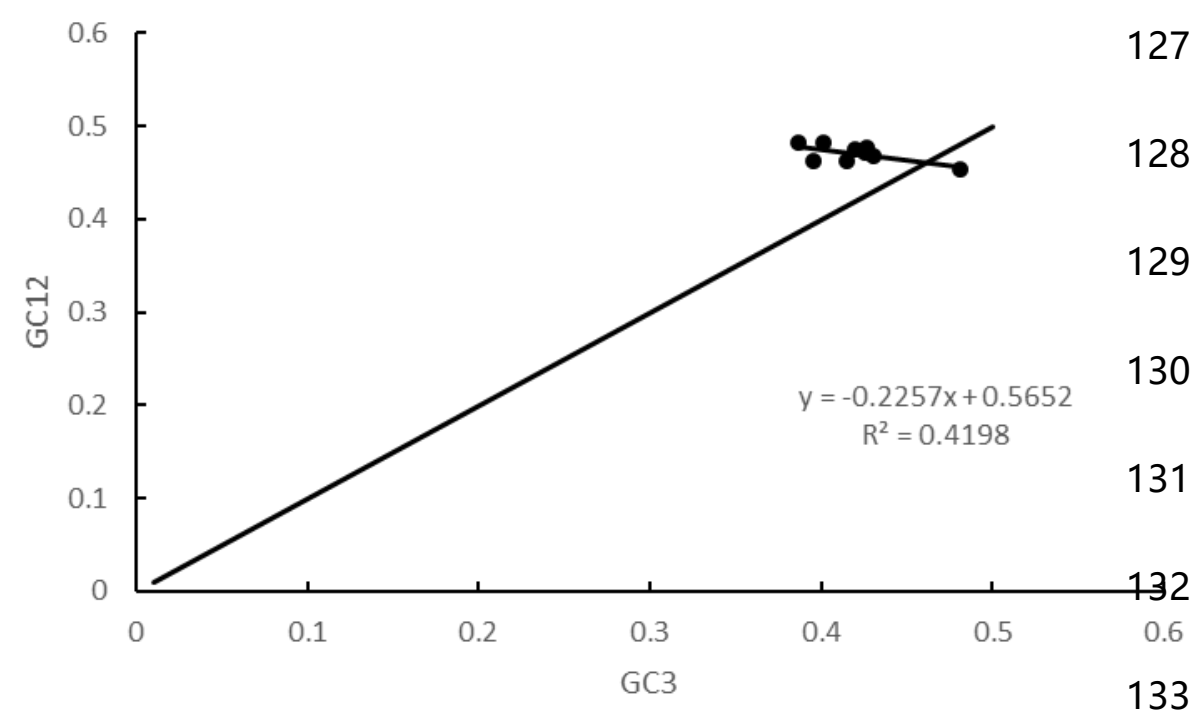

136 ENC-plot results were shown as Fig.2. Seen from Fig.2, ENC value changed between 36.08 and

13749.55 , and mean was 44.98. Change range of GC3S content was between $38.20 \%$ and $47.70 \%$, with

$13841.26 \%$ of mean. Standard curve in Fig.2 showed that codon usage was only affected by mutation,

139 while the points represented by each gene were distributed in the middle and lower part of the 140 standard curve. It illustrated that mutation had a weak effect on the formation of codon preference

141 in the mitochondrial genome of $E$. fuscoguttatus. To more accurately reflect the difference between

142 actual and predicted $\mathrm{ENC}$ values, $\mathrm{ENC}_{\text {ratio }}$ was calculated according to the formula (2), and

143 frequency distribution of $\mathrm{ENC}_{\text {ratio }}$ was counted (Table 4). Statistical results showed that $44.44 \%$ of

144 genes were distributed between 0.15 and 0.2 , while $22.22 \%$ of genes were distributed between 0.2

145 and 0.25 . The distribution of $11.11 \%$ genes ranged from 0.25 to 0.3 , and $11.11 \%$ genes ranged from

1460.3 to 0.35 , and $11.11 \%$ genes ranged from 0.35 to 0.4 . Therefore, it illustrated that selection was

147 main factor in the formation of codon preference in mitochondrial genome of E. fuscoguttatus. 


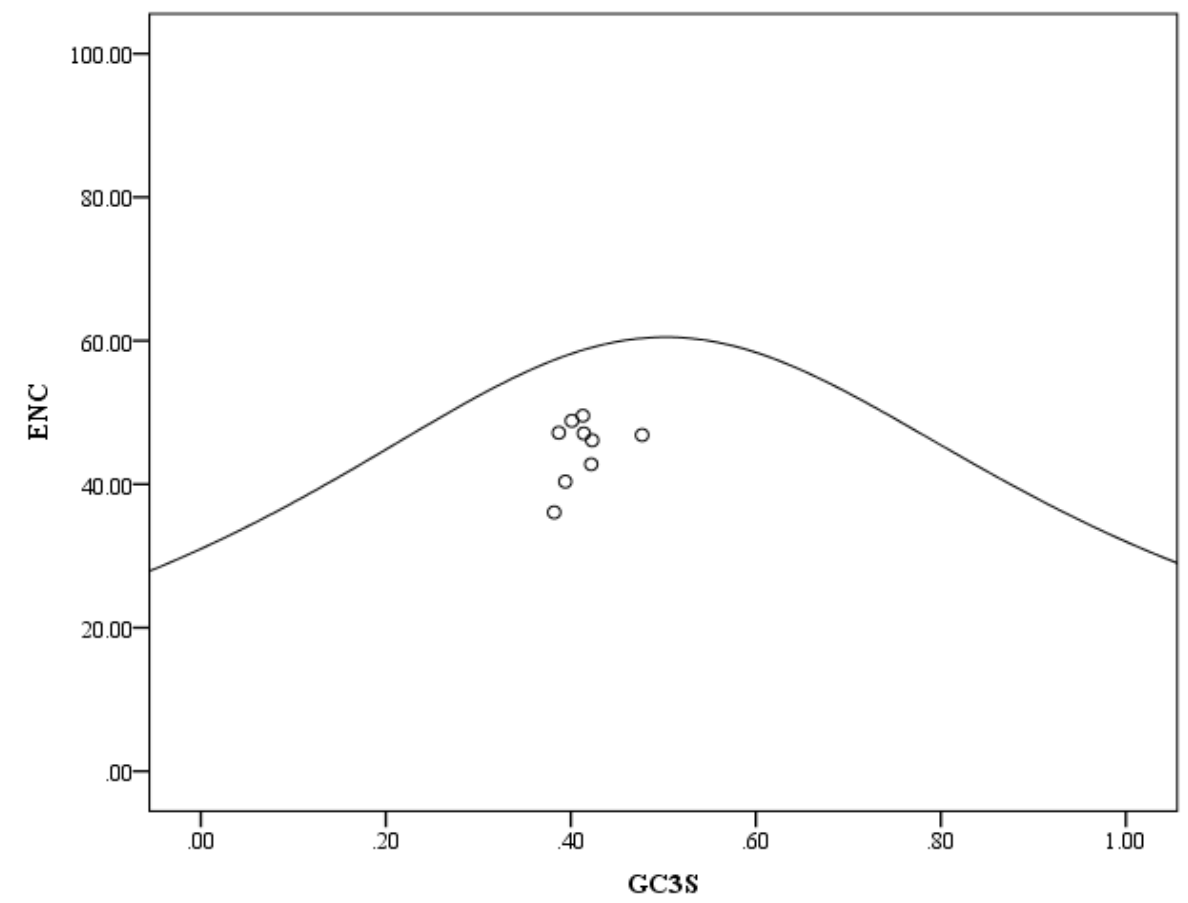

Fig.2 ENC-plot analysis of mitochondrial genes in E. fuscoguttatus

\begin{tabular}{ccc}
\hline Group & Number & Frequency / \% \\
\hline $0.15 \sim 0.2$ & 4 & 44.44 \\
$0.2 \sim 0.25$ & 2 & 22.22 \\
$0.25 \sim 0.3$ & 1 & 11.11 \\
$0.3 \sim 0.35$ & 1 & 11.11 \\
$0.35 \sim 0.4$ & 1 & 11.11 \\
\hline
\end{tabular}

156 Correspondence analysis results of RSCU showed that the first axis contributed $58.85 \%$ of

157 difference, while the second, third and fourth axes contributed $14.59 \%, 7.66 \%$ and $5.43 \%$ of

158 difference. Total contribution rate of the first four vectors was $85.53 \%$. The first axis had the

159 maximum contribution rate, while contribution rates of other axes decreased in turn, illustrating that 
160 the first axis was main influence factor of codon preference. Correlation coefficients between the

161 first axis and GC3, ENC were respectively 0.016 and 0.376 , and there was no significant correlation.

162 It illustrated that GC3 caused little impact on codon preference of mitochondrial genome in $E$.

163 fuscoguttatus. To more intuitively observe codon preference, taking the first axis as horizontal

164 ordinate and the second axis as vertical ordinate, 59-dimension spatial orthogonal axes were

165 obtained (Fig.3). Seen from Fig.3, the distribution of each gene was scattered because of different

166 codon preference.

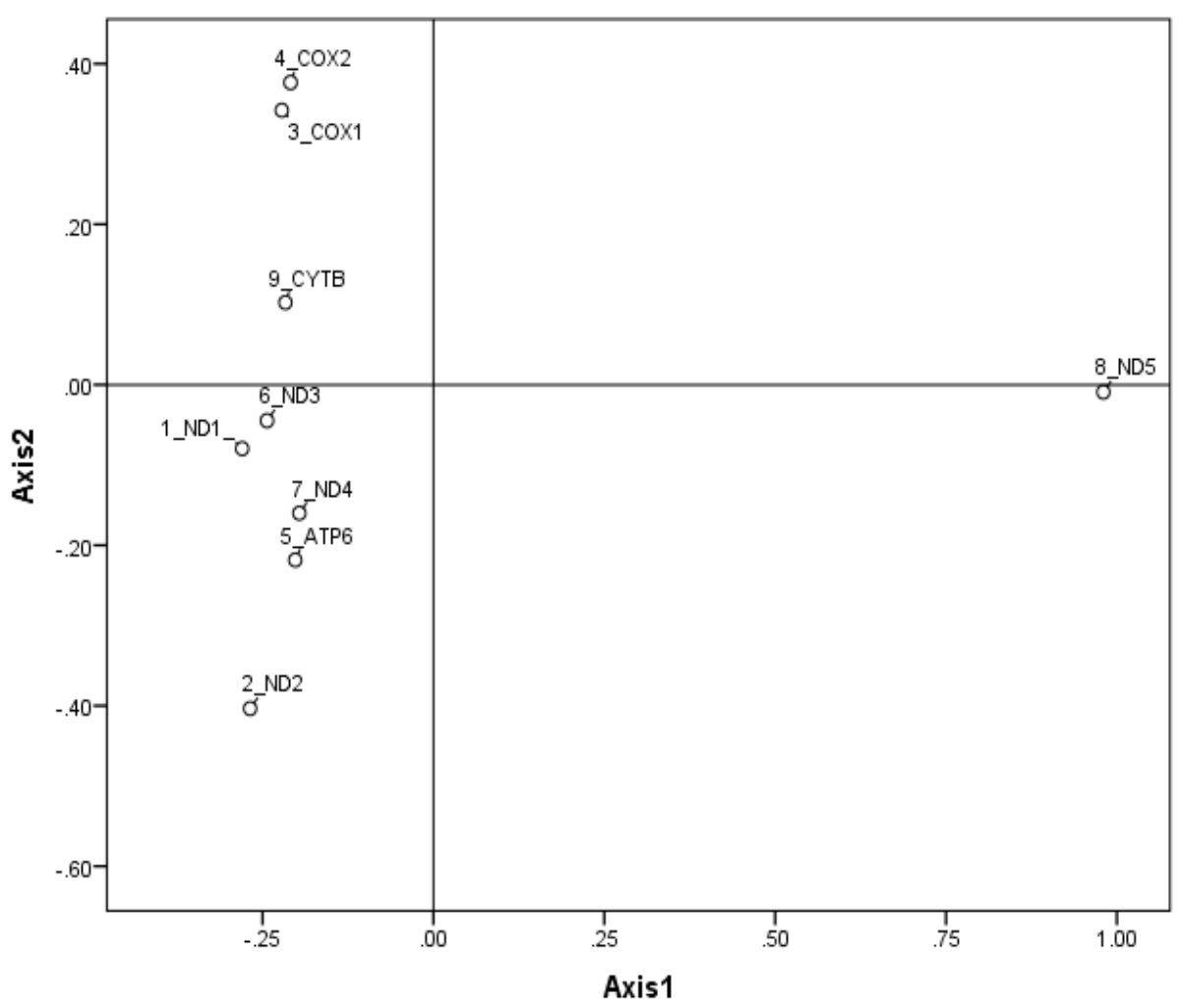

167

Fig.3 Corresponding analysis based on RSCU

169 2.6 Determination of optimal codon

170 Taking ENC value as the standard, CDS sequences of all genes were sequenced, and then $20 \%$ of

171 the genes were selected from each end. Highly expressed gene bank composed of ATP6 and ND5 
172 and lowly expressed gene bank composed of ND1 and ND3 were screened out. Software

173 Codonw1.4.2 was used to calculate RSCU values of the two banks, as well as $\triangle$ RSCU value (Table

174 5). Taking $\triangle \mathrm{RSCU}>0.08$ as the standard, 32 highly expressed codons were determined finally

175 (codons marked by * in Table 5). Among them, three codons ended with A, 14 codons ended with

$176 \mathrm{U}, 10$ codons ended with $\mathrm{G}$, and four codons ended with $\mathrm{C}$.

17732 highly expressed codons determined in Table 5 and 32 high-frequency codons in Table 3 were

178 analyzed, and common codon was chosen as the optimal one. Mitochondrial genome of $E$.

179 fuscoguttatus had nine optimal codons, and they were CUU, AUC, GUU, CCU, GCA, UAU, CGC,

180 AGC and GGC. Among them, four codons ended with $\mathrm{U}$, four codons ended with $\mathrm{C}$, one codon

181 ended with A, and there was no codon ended with G.

1823 Discussion

183 By analyzing GC content and RSCU of mitochondrial genome in E. fuscoguttatus, it was found

184 that there were 32 codons with RSCU $>1$, and 26 codons ended with A/C. So, E. fuscoguttatus

185 preferred codons ending with A/C. The research showed that coding genes of mitochondrial protein

186 of Coregonus lavaretus preferred codons ending with $\mathrm{A} / \mathrm{C}$ in base composition ${ }^{[29]}$; the codons of

187 mitochondrial genome of Hynobiidae, Pyricularia oryzae Cav and Oryza rufipogon Griff, and

188 NADH dehydrogenase subunit gene preferred to end with $\mathrm{A} / \mathrm{U}^{[10,31-33]}$; Acanthopagrus schlegelii

189 and Pagrus major preferred codons ending with $\mathrm{G} / \mathrm{C}^{[34]}$. It showed that there were differences in

190 codon usage of mitochondrial gene among different organisms. Average GC content of

191 mitochondrial gene of E. fuscoguttatus was $45.40 \%$, which was higher than that of Hynobiidae and

192 pathogenic bacteria of O. rufipogon Griff ${ }^{[10,31]}$, and was lower than that of C. lavaretus was low ${ }^{[29]}$.

193 It illustrated that there was difference in GC content of different biological groups. 
195 for affecting codon preference ${ }^{[4]}$. ENC-plot analysis results showed that mean ENC of codon of mitochondrial genome of E. fuscoguttatus was 41.26. Jiang et al. ${ }^{[35]}$ took 35 of ENC as

197 distinguishing standard of bias. When ENC was more than 35, it was codon with weak preference.

198 When ENC was less than 35, it was codon with strong preference. It illustrated that codons of 199 mitochondrial genome in E. fuscoguttatus had weak preference, and CAI mean was 0.155 , which 200 also supported the opinion.

201 Neutral plot analysis results showed that there was no significant correlation between GC12 and 202 GC3, and slope was smaller, illustrating that selection was main factor causing codon preference.

203 ENC-plot analysis results also illustrated the opinion. In the chart, all the genes were located in the

204 lower middle of the standard curve and far away from the curve, and there was larger difference 205 between actual and theoretical ENC values. Therefore, it was thought that selection was main cause 206 affecting codon usage preference of mitochondrial genome of E. fuscoguttatus. It was the same with 207 the conclusions of more than 20 kinds of Hynobius, such as Hynobius arisanensis, Hynobius 208 formosanus, Hynobius amjiensis ${ }^{[31]}$, and many kinds of insects, such as Eurydema dominulus ${ }^{[16,36]}$.

209 In construction of heterologous expression system, different species have different codon usage 210 preferences ${ }^{[37]}$. Therefore, it has important significance for optimizing and transforming genes, 211 promoting translation efficiency, and improving expression of foreign genes to analyze codon usage 212 patterns of species ${ }^{[34]}$. In this paper, the combination method of codons with high expression and 213 high frequency was used to determine the codon shared by them as the optimal one, and nine codons 214 were finally determined as optimal codons of mitochondrial genome of E. fuscoguttatus: CUU, 215 AUC, GUU, CCU, GCA, UAU, CGC, AGC and GGC. The research could provide theoretical basis 
216 for carrying out breeding improvement of E. fuscoguttatus from genetic essence by optimizing and

217 transforming genes, and improving expression efficiency of foreign genes.

2184 Conclusions

219 Codon usage preference of mitochondrial genome of E. fuscoguttatus was weak, and it preferred

220 codons ending with $\mathrm{A}$ or $\mathrm{U}$, and the formation of codon preference was mainly affected by selection.

221 Meanwhile, nine codons (CUU, AUC, GUU, CCU, GCA, UAU, CGC, AGC and GGC) were

222 determined as optimal codons of mitochondrial genome of E. fuscoguttatus. Above analysis results

223 could provide theoretical basis for analyzing its gene expression, high expression of foreign genes,

224 and molecular evolution.

2255 methods

2265.1 Sequence source

227 Mitochondrial genome of E. fuscoguttatus was searched and downloaded from NCBI database

228 (https://www.ncbi.nlm.nih.gov/nuccore/MK791189.1), and a total of 26 CDS (coding DNA

229 sequence) were downloaded. To reduce sample error, the repetitive sequences were eliminated firstly,

230 and then nine gene sequences with ATG as the starting codon and length greater than $300 \mathrm{bp}$ were

231 selected for analysis (Table 6).

232

Table 6 Length of gene sequence

\begin{tabular}{cc}
\hline Gene & Length // bp \\
\hline ND1 & 974 \\
ND2 & 1044 \\
COX1 & 1550 \\
COX2 & 690
\end{tabular}


ND5

$234 \quad$ 5.2.1 Analysis of codon preference parameters.

235 Software Codonw 1.4.2 was used to respectively calculate total GC content (GC), GC content of 236 synonymous codon on the third position (GC3S), relative synonymous codon usage (RSCU), 237 effective number of codon (ENC), codon adaption index (CAI), codon bias index (CBI), frequency 238 of optimal codons (FOP), grand average of hydropathy (Gravy) of DNA sequences of nine protein 239 coding genes. GC contents of codons on the first, second and third positions were showed by GC1,

$240 \mathrm{GC} 2$ and GC3, while the mean of GC1 and GC2 was showed by GC12.

$241 \quad 5.2 .2$ Neutral plot analysis.

242 Neutral plot analysis is a analytic method to measure whether codon usage preference is affected

243 by mutation or selection. Neutral plot analysis took the mean GC12 calculated by GC1 and GC2 as

244 vertical ordinate, and $\mathrm{GC} 3$ as horizontal ordinate, to make scatter plot. In the chart, each point 245 represents an independent gene. By analyzing the relationship among the first, second and third 246 bases composition of codons, whether codon usage preference was affected by mutation or selection 247 was judged.

$248 \quad$ 5.2.3ENC-plot mapping

249 ENC-plot mapping took ENC as vertical ordinate and GC3S as horizontal ordinate, to make 
scatter plot. Each gene was located in the scatter plot, and standard curve of ENC value was added,

251 and standard curve equation ${ }^{[27]}$ was:

252

253

$$
\mathrm{ENC}_{\mathrm{exp}}=2+\mathrm{GC} 3 \mathrm{~S}+\frac{29}{\mathrm{GC}^{2} \mathrm{~S}^{2}+(1-\mathrm{GC} 3 \mathrm{~S})^{2}}
$$

$$
\text { ENC ratio: } \mathrm{ENC}_{\text {ratio }}=\frac{\mathrm{ENC}_{\exp }-\mathrm{ENC}_{\text {obs }}}{\mathrm{ENC}_{\exp }}
$$

According to scatter plot and distribution results of $\mathrm{ENC}_{\text {ratio, }}$ if the gene was located on or along the standard curve, the codon preference was only affected by mutation; if the gene was located far below the standard curve, the codon preference was affected by selection.

\subsubsection{Correspondence analysis.}

Correspondence analysis is a multivariate statistical analysis method in codon usage patterns. Via software Codonw, correspondence analysis was used for codon analysis of mitochondrial genome of E. fuscoguttatus, which was helpful to understand the internal law of codon distribution in mitochondrial genome of E. fuscoguttatus.

\subsubsection{Determination of optimal codon.}

$\Delta \mathrm{RSCU}$ method ${ }^{[28]}$ was used to determine optimal codon. ENC value was sequenced, and $20 \%$ genes were selected from each end to establish gene banks of high and low expression, and then $\triangle \mathrm{RSCU}$ of gene banks of high and low expression was calculated. If $\triangle \mathrm{RSCU}$ was more than 0.08 , and RSCU value of the codon was more than 1 in gene bank of high expression, it was determined as optimal codon.

\section{abbreviations}

RSCU: relative synonymous codon usage; ENC: effective number of codon; CAI: codon adaption index; CBI :codon bias index; FOP: frequency of optimal codons; Gravy: grand average of hydropathy; Amoro: Amoromaticity; 


\section{Declaration}

273 Ethics approval and consent to participate:

274 All authors are willing to participate in this study and the experiment was conducted according

275 to the guidelines established by Beibu Gulf University .

\section{Consent for publication}

277 All authors are consent for publication

278 Availability of data and materials

279 All data are included in this manuscript; data sharing is not applicable to this article.

280 Competing interests:

281 The authors declare that they have no competing interests.

\section{Funding}

283 This work was supported by the Guangxi Key R\&D Program (2018AB52002); National Key

284 R\&D Program of China (2018YFD0901406); Guangxi Natural Science Foundation Program

285 (2021GXNSFAA075008); the National Natural Science Foundation of China (31873042);

286 Guangxi Key Laboratory of Marine Biodiversity Conservation Program (2021ZB02); Young and

287 middle-Aged Teachers' Basic Ability Improvement Project in Colleges and Universities of

288 Guangxi (2018KY0612) and State Oceanic Administration Project: Beihai City’s "Thirteenth

289 Five-Year" Marine Economic Innovation and Development Demonstration Project (Bhsf002).

290 Authors' contributions:

291 BLR, LLL and YDH carried out data collation, writing review, editing, funding acquisition and 292 project administration; LSP, HJC, CJ, WP, GY and WHC done data collation, writing review and 293 editing. 
294 Acknowledgment:

$295 \quad$ Not Applicable

296

297

298

299

300

301

302

303

304

305

306

307

308

309

310

311

312

313

314

315 


\section{References}

317 [1] Duan XK. Studies on Complete Mitochondrial Genome of Parabramis Pekinensis Strenosoma And

318 Codon Usage Patterns of Megalobrama Amblycephala. Hua Zhong Agricultural University, 2015.

$319 \quad$ (in chinese)

320 [2] Wang PL, Wu SC, Yang LP, Wang HY, Chen NM. Analysis of codon bias of chloroplast genome in Eucalyptus grandis. Guihaia, 2019, 39(12): 1583-1592. (in chinese)

322 [3] Lu QF, Huang ZH, Luo WH. Analysis of Codon Usage Bias of WRKY Transcription Factors in Tomato. Molecular Plant Breeding, 2020, 18(18): 5908-5916. (in chinese)

324 [4] Hershberg R, Petrov DA. Selection on Codon Bias. Annual Review of Genetics, 2008, 42: 287299.

326 [5] Moriyama EN, Powell JR. Gene length and codon usage bias in Drosophila melanogaster, Saccharomyces cerevisiae and Escherichia coli. Nucleic Acids Research, 1998, 26(13): 31883193.

[6] Ermolaeva MD. Synonymous codon usage in bacteria. Current Issues in Molecular Biology, 2001, 3(4): 91-97.

331 [7] Carlini DB, Chen Y, Stephan W. The relationship between third-codon position nucleotide content, codon bias, mRNA secondary structure and gene expression in the drosophilid alcohol dehydrogenase genes Adh and Adhr. Genetics, 2001, 159(2): 623-633.

334 [8] Liberatore KL, Dukowic SS, Miller M, Chen C, Kianian SK. The role of mitochondria in plant 335 development and stress tolerance. Free Radical Biology \& Medicine, 2016, 238-256.

336 [9] Curole JP, Kocher TD. Mitogenomics: digging deeper with complete mitochondrial genomes ScienceDirect. Trends in Ecology \& Evolution, 1999, 14(10): 394-398. 
338 [10] Jin G, Wang LP, Long LY, Wu F, Tang YJ, Tan JF, Wei DN, Huang QW, Su WP. Analysis of 339 codon usage bias in the mitochondrial protein-coding genes of Oryza rufipogon. Plant Science $340 \quad$ Journal, 2019, 37(02): 188-197. (in chinese)

341 [11] Zhang WJ. Codon Analysis and Its Applieation in Bioinformaties and Evolutionary Studies. Fudan University, 2006. (in chinese)

343 [12] Liang XF, Tian XL, Liu WK, Wei TY, Wang W. Comparative analysis of the mitochondrial

[13] Li L, Hong W, Li Z, Luo XZ, Hu GF, Zhang ZW, Zhu YY, Chu GW. Sequence and phylogeny analysis of the complete mitochondrial genome of Pelteobagrus vachelli. Hereditas, 2011,

[14] Meng Q, Zhang ZY, Zhang ZW, Zhang CJ, Chen SY, Zhu F, Jia CF, Cao GY. Codon Bias and 33(06): 627-635. (in chinese) Rock Bream O.fasciatus. Fisheries Science, 2020, 39(05):702-709. (in chinese)

[15] Zhao WQ, Zhang M, Liu J, Gao ZZ, Yi WB, Liu DJ. The Research of Codon Usage Bias in Mitochondrial Genome of Aquarius paludum and the Adaptive Evolution of COI Gene. Anhui Agricultural Science Bulletin, 2020, 26(08):10-14. (in chinese)

[16] Zhao WQ, Zhang M, Liu DJ, Lei H, Yi WB, Liu J, Gao ZZ, Zhang HF. Analysis of Codon Usage Bias in Mitochondrial Genome of Eurydema dominulus. Journal of Shanxi Agricultural Sciences, 2020, 48(07): 1005-1009. (in chinese)

[17] Tang XM, Yang SZ, Chen HZ, Sun ZD, Lai ZG, Ceng WY, Wei QY. Comparative analysis on codon usage bias in mitogenome of two species in genus Glycine. Guihaia, 2020, 40(07): 926-934. (in 
chinese)

361 [18] Li XZ, Song H, Li CJ. Analysis of Codon Usage Bias in Mitochondria Genome of Fusarium solani. Genomics and Applied Biology, 2015, 34(11): 2465-2472. (in chinese)

363 [19] Nelson JS, Grande TC, Wilson MVH. Fishes of the World, 5th Edition. 2016.

364 [20] Baldwin CC, Johnson GD. FAO Species Catalogue. Vol. 16. Groupers of the World (Family Serranidae,Subfamily Epinephelinae). An Annotated and Illustrated Catalogue of the Grouper, Rockcod, Hind, Coral Grouper, and Lyretail Species Known to Date, by Phillip C. Heemstra; John E. Randall. FAO, 1993.

368 [21] Bai LR, Zhao YZ. Study on Embryonic Development, Larva, Juvenile and Young Fish of Epinephelus fuscoguttatus. Agricultural Science \& Technology, 2016, 17(06):1305-1314.

[22] Liao JQ, Yi SW, Chen GH, Huang H, Lei CG, Lou TT. The Karyotype of Grouper Epinephelus fuscoguttatus. Fisheries Science, 2006(11):567-569. (in chinese)

[23] Fan YJ, Wei YB, Xu XH, Sun A, Jiang GJ. Establishment of Three Cell Lines from BrownMarbled Grouper, Epinephelus Fuscoguttatus. Periodical of Ocean University of China, 2009,

[24] Shi G, Zhang JD, Pan CH, Huang JS, Tang BG, Zhou H, Wang ZL, Chen G. Effect of Gradient and Acute Salinity Stress Experiment on Survivorship and Food Intake of Brown-marbled Grouper, Epinephelus fuscoguttatus. Journal of Guangdong Ocean University, 2011,

[25] Shapawi R, Ebi I, Yong A S K, et al. Optimizing the growth performance of brown-marbled grouper, Epinephelus fuscoguttatus (Forskal), by varying the proportion of dietary protein and lipid levels. Animal Feed Science and Technology, 2014, 191:98-105. 
[26] Lin MD. Comparative Analysis of Hybrid Grouper (Epinephelus fuscoguttatus $9 \times \mathrm{E}$. polyphekadion ${ }^{\widehat{ }}$ ) and its Female Parent Tiger Grouper (E. fuscoguttatus) Based on Transcriptome Sequencing. Guangdong Ocean University, 2019. (in chinese)

385 [27] Wright F. The effective number of codons used in a gene. Gene, 1990, 87(1): 23-29.

386 [28] Shang ZM, Liu F, Hua JH, Wang KB. Analysis on Codon Usage of Chloroplast Genome of Gossypium hirsutum. Scientia Agricultura Sinica, 2011, 44(02):245-253. (in chinese)

388 [29] Zhu XF, Guo YC, Mi Q, Liu D. Analysis on Codon Usage of Mitochondrial Protein - coding Genes of Coregonus lavaretus. Journal of Southeast Guizhou National Teachers College, 2015, 33(06):60-63. (in chinese)

[30] Sharp PM, Li WH. The Codon Adaptation Index--a measure of directional synonymous codon usage bias, and its potential applications. Nucleic acids research,1987,15(3):1281-1295.

393 [31] Jiang Y. Analysis of codon bias and evolutionary relationship in mitochondrial genome of Hynobiidae. Shaanxi Normal University, 2016. (in chinese)

[32] Xu SL, Wang JF, Chen SH. Analysis on codon usage preference of mitochondria genome of Magaporthe orisea. Journal of Henan Agricultural University, 2013, 47(06): 722-726. (in chinese)

397 [33] Wang PF, Gao HH, Su L, Jiang XL, Wu XY, Yang LY, Ren FS, Wang YM. Comprehensive Analysis of Codon Usage Bias of Drosophila melanogaster and D. sechellia mitochondrion and NADH dehydrogenase subunit Gene Family. Anhui Agricultural Science, 2018, 46 (01):96-101. (in chinese) of the microsatellite sequences and codon bias of the coding sequence in Acanthopagrus schlegelii, Pagrus major and their hybrid progenies. Oceanologia Et Limnologia Sinica, 2019, 
[35] Jiang Y, Deng F, Wang H, Hu Z. An extensive analysis on the global codon usage pattern of baculoviruses. Archives of virology, 2008, 153(12):2273-2282.

407 [36] Sang LQ. Codon bias and evolution of mitochondrial genes in insects. Shaanxi Normal 408 University, 2019. (in chinese)

409

[37] Liu CL, Chen A M, Liu YQ, Cao M, Chen Q. Analysis on Codon Usage Bias of Mylabris phalerata Pallas Transcriptome Coding Sequence. Chinese Journal of Information on Traditional Chinese Medicine, 2020, 27(10): 64-68. (in chinese)

412

413

414

415

416

417

418

419

420

421

422

423

424

425 
Table 3 Relative synonymous codon usage analysis of mitochondrial genes in E. fuscoguttatus

\begin{tabular}{|c|c|c|c|c|c|c|c|}
\hline Amino & Codon & Number & RSCU & Amino & Codon & Number & $\mathrm{RSCU}$ \\
\hline \multirow[t]{2}{*}{ Phe } & UUU & 77 & 0.92 & Ser & $\mathrm{UCU}$ & 44 & 1.23 \\
\hline & UUC & 90 & 1.08 & & UCC & 55 & 1.53 \\
\hline \multirow[t]{6}{*}{ Leu } & UUA & 77 & 0.86 & & UCA & 49 & 1.37 \\
\hline & UUG & 9 & 0.1 & & UCG & 5 & 0.14 \\
\hline & CUU & 132 & 1.47 & & $\mathrm{AGU}$ & 19 & 0.53 \\
\hline & CUC & 128 & 1.42 & & AGC & 43 & 1.2 \\
\hline & CUA & 157 & 1.74 & Pro & $\mathrm{CCU}$ & 87 & 1.43 \\
\hline & CUG & 37 & 0.41 & & $\mathrm{CCC}$ & 83 & 1.36 \\
\hline \multirow[t]{3}{*}{ Ile } & AUU & 110 & 1.09 & & $\mathrm{CCA}$ & 61 & 1 \\
\hline & AUC & 110 & 1.09 & & CCG & 13 & 0.21 \\
\hline & AUA & 84 & 0.83 & Thr & $\mathrm{ACU}$ & 61 & 0.93 \\
\hline Met & AUG & 33 & 1 & & $\mathrm{ACC}$ & 93 & 1.43 \\
\hline \multirow[t]{4}{*}{ Val } & GUU & 45 & 1.22 & & $\mathrm{ACA}$ & 96 & 1.47 \\
\hline & GUC & 39 & 1.06 & & ACG & 11 & 0.17 \\
\hline & GUA & 49 & 1.33 & Ala & GCU & 38 & 0.67 \\
\hline & GUG & 14 & 0.38 & & GCC & 100 & 1.77 \\
\hline \multirow[t]{2}{*}{ Tyr } & UAU & 59 & 1.02 & & GCA & 84 & 1.49 \\
\hline & UAC & 57 & 0.98 & & GCG & 4 & 0.07 \\
\hline Cys & UGU & 12 & 0.69 & TER & UAA & 12 & 0.38 \\
\hline
\end{tabular}




\begin{tabular}{|c|c|c|c|c|c|c|c|}
\hline & UGC & 23 & 1.31 & & UAG & 2 & 0.06 \\
\hline \multirow[t]{2}{*}{ His } & CAU & 39 & 0.67 & & UGA & 80 & 2.55 \\
\hline & CAC & 77 & 1.33 & $\operatorname{Trp}$ & UGG & 16 & 1 \\
\hline \multirow[t]{2}{*}{ Gln } & CAA & 72 & 1.62 & Arg & $\mathrm{CGU}$ & 16 & 0.82 \\
\hline & CAG & 17 & 0.38 & & CGC & 29 & 1.49 \\
\hline \multirow[t]{2}{*}{ Asn } & AAU & 59 & 0.9 & & CGA & 39 & 2 \\
\hline & AAC & 72 & 1.1 & & CGG & 5 & 0.26 \\
\hline \multirow[t]{2}{*}{ Lys } & AAA & 63 & 1.73 & Arg & AGA & 12 & 0.62 \\
\hline & $\mathrm{AAG}$ & 72 & 1.1 & & AGG & 16 & 0.82 \\
\hline \multirow[t]{2}{*}{ Asp } & GAU & 13 & 0.42 & Gly & GGU & 33 & 0.8 \\
\hline & GAC & 49 & 1.58 & & GGC & 58 & 1.4 \\
\hline \multirow[t]{2}{*}{ Glu } & GAA & 58 & 1.71 & & GGA & 52 & 1.25 \\
\hline & GAG & 10 & 0.29 & & GGG & 23 & 0.55 \\
\hline
\end{tabular}

428

429 Table 5 Relative synonymous codon usage of highly and lowly expressed gene banks of

430 mitochondrial genes in E. fuscoguttatus

\begin{tabular}{ccccccc}
\hline \multirow{2}{*}{ Amino acid } & Codon & \multicolumn{2}{c}{ Highly expressed genes } & \multicolumn{2}{c}{ Lowly expressed genes } & \multirow{2}{*}{ ARSCU } \\
\cline { 3 - 6 } & & Number & RSCU & Number & RSCU & \\
\hline \multirow{2}{*}{ Phe } & UUU $^{* *}$ & 20 & 1.25 & 13 & 1 & 0.25 \\
& UUC & 12 & 0.75 & 13 & 1 & -0.25 \\
Leu & UUA & 13 & 0.66 & 17 & 1.1 & -0.44
\end{tabular}




\begin{tabular}{|c|c|c|c|c|c|c|}
\hline & UUG & 3 & 0.15 & 3 & 0.19 & -0.04 \\
\hline & $\mathrm{CUU}^{* * *}$ & 40 & 2.02 & 22 & 1.42 & 0.6 \\
\hline & CUC & 25 & 1.26 & 19 & 1.23 & 0.03 \\
\hline & CUA & 24 & 1.21 & 28 & 1.81 & -0.6 \\
\hline & $\mathrm{CUG}^{* *}$ & 14 & 0.71 & 4 & 0.26 & 0.45 \\
\hline lle & AUU & 16 & 1.02 & 15 & 1.07 & -0.05 \\
\hline & $\mathrm{AUC}^{*}$ & 22 & 1.4 & 17 & 1.21 & 0.19 \\
\hline & AUA & 9 & 0.57 & 10 & 0.71 & -0.14 \\
\hline Met & AUG & 10 & 1 & 2 & 1 & 0 \\
\hline Val & GUU* & 8 & 1.39 & 6 & 1.26 & 0.13 \\
\hline & GUC & 7 & 1.22 & 6 & 1.26 & -0.04 \\
\hline & GUA & 7 & 1.22 & 6 & 1.26 & -0.04 \\
\hline & GUG & 1 & 0.17 & 1 & 0.21 & -0.04 \\
\hline Ser & $\mathrm{UCU}$ & 12 & 1.09 & 6 & 1.33 & -0.24 \\
\hline & UCC & 10 & 0.91 & 8 & 1.78 & -0.87 \\
\hline & UCA & 6 & 0.55 & 10 & 2.22 & -1.67 \\
\hline & $\mathrm{UCG}^{*}$ & 1 & 0.09 & 0 & 0 & 0.09 \\
\hline Pro & $\mathrm{CCU}^{* * *}$ & 50 & 2.02 & 11 & 1.38 & 0.64 \\
\hline & $\mathrm{CCC}$ & 23 & 0.93 & 14 & 1.75 & -0.82 \\
\hline & $\mathrm{CCA}$ & 19 & 0.77 & 7 & 0.88 & -0.11 \\
\hline & $\mathrm{CCG}^{*}$ & 7 & 0.28 & 0 & 0 & 0.28 \\
\hline Thr & $\mathrm{ACU} * * *$ & 26 & 1.58 & 7 & 0.85 & 0.73 \\
\hline
\end{tabular}




\begin{tabular}{|c|c|c|c|c|c|c|}
\hline & $\mathrm{ACC}$ & 16 & 0.97 & 14 & 1.7 & -0.73 \\
\hline & $\mathrm{ACA}$ & 19 & 1.15 & 12 & 1.45 & -0.3 \\
\hline & $\mathrm{ACG}^{* *}$ & 5 & 0.3 & 0 & 0 & 0.3 \\
\hline \multirow[t]{4}{*}{ Ala } & $\mathrm{GCU}^{* * *}$ & 6 & 1 & 5 & 0.45 & 0.55 \\
\hline & GCC & 7 & 1.17 & 25 & 2.27 & -1.1 \\
\hline & $\mathrm{GCA}^{* *}$ & 10 & 1.67 & 13 & 1.18 & 0.49 \\
\hline & $\mathrm{GCG}^{*}$ & 1 & 0.17 & 1 & 0.09 & 0.08 \\
\hline \multirow[t]{2}{*}{ Tyr } & UAU* & 26 & 1.33 & 8 & 1.14 & 0.19 \\
\hline & UAC & 13 & 0.67 & 6 & 0.86 & -0.19 \\
\hline \multirow[t]{2}{*}{ TER } & $\mathrm{UAA}^{* * *}$ & 10 & 1.5 & 1 & 0.27 & 1.23 \\
\hline & $\mathrm{UAG}^{* *}$ & 2 & 0.3 & 0 & 0 & 0.3 \\
\hline \multirow[t]{2}{*}{ His } & $\mathrm{CAU}^{*}$ & 24 & 0.94 & 2 & 0.8 & 0.14 \\
\hline & CAC & 27 & 1.06 & 3 & 1.2 & -0.14 \\
\hline \multirow[t]{2}{*}{ Gln } & CAA & 24 & 1.45 & 8 & 1.78 & -0.14 \\
\hline & $\mathrm{CAG}^{* *}$ & 9 & 0.55 & 1 & 0.22 & 0.33 \\
\hline \multirow[t]{2}{*}{ Asn } & $\mathrm{AAU}^{* *}$ & 34 & 1.15 & 5 & 0.77 & 0.38 \\
\hline & $\mathrm{AAC}$ & 25 & 0.85 & 8 & 1.23 & -0.38 \\
\hline \multirow[t]{2}{*}{ Lys } & AAA & 18 & 1.44 & 7 & 1.75 & -0.31 \\
\hline & $\mathrm{AAG}^{* *}$ & 7 & 0.56 & 1 & 0.25 & 0.31 \\
\hline \multirow[t]{2}{*}{ Asp } & GAU*** & 3 & 1.2 & 1 & 0.22 & 0.98 \\
\hline & GAC & 2 & 0.8 & 8 & 1.78 & -0.98 \\
\hline Glu & GAA & 6 & 1.5 & 15 & 1.88 & -0.38 \\
\hline
\end{tabular}




\begin{tabular}{|c|c|c|c|c|c|c|}
\hline & $\mathrm{GAG}^{* *}$ & 2 & 0.5 & 1 & 0.13 & 0.37 \\
\hline \multirow[t]{2}{*}{ Cys } & $\mathrm{UGU}^{* *}$ & 8 & 0.73 & 0 & 0 & 0.73 \\
\hline & UGC & 14 & 1.27 & 1 & 2 & -0.73 \\
\hline TER & UGA & 8 & 1.2 & 10 & 2.73 & -1.53 \\
\hline $\operatorname{Trp}$ & UGG & 10 & 1 & 3 & 1 & 0 \\
\hline \multirow[t]{4}{*}{ Arg } & $\mathrm{CGU}^{* * *}$ & 7 & 0.61 & 0 & 0 & 0.61 \\
\hline & $\mathrm{CGC}$ & 0 & 0 & 0 & 0 & 0 \\
\hline & CGA & 9 & 0.78 & 9 & 5.4 & -4.62 \\
\hline & $\mathrm{CGG}^{* *}$ & 5 & 0.43 & 0 & 0 & 0.43 \\
\hline \multirow[t]{2}{*}{ Ser } & $\mathrm{AGU}^{* * *}$ & 15 & 1.36 & 1 & 0.22 & 1.14 \\
\hline & $\mathrm{AGC}^{* * *}$ & 22 & 2 & 2 & 0.44 & 1.56 \\
\hline \multirow[t]{2}{*}{ Arg } & $\mathrm{AGA}^{* * *}$ & 12 & 1.04 & 0 & 0 & 1.04 \\
\hline & $\mathrm{AGG}^{* * *}$ & 16 & 1.39 & 0 & 0 & 1.39 \\
\hline \multirow[t]{4}{*}{ Gly } & $\mathrm{GGU}^{* *}$ & 4 & 0.94 & 3 & 0.5 & 0.44 \\
\hline & $\mathrm{GGC}^{* *}$ & 7 & 1.65 & 8 & 1.33 & 0.32 \\
\hline & GGA & 4 & 0.94 & 12 & 2 & -1.06 \\
\hline & $\mathrm{GGG}^{* *}$ & 2 & 0.47 & 1 & 0.17 & 0.3 \\
\hline
\end{tabular}

$431 \quad$ Note: * means $\triangle \mathrm{RSCU}>0.08$; ** means $\Delta \mathrm{RSCU}>0.3 ; * * *$ means $\Delta \mathrm{RSCU}>0.5$.

432

433

434 
Figures

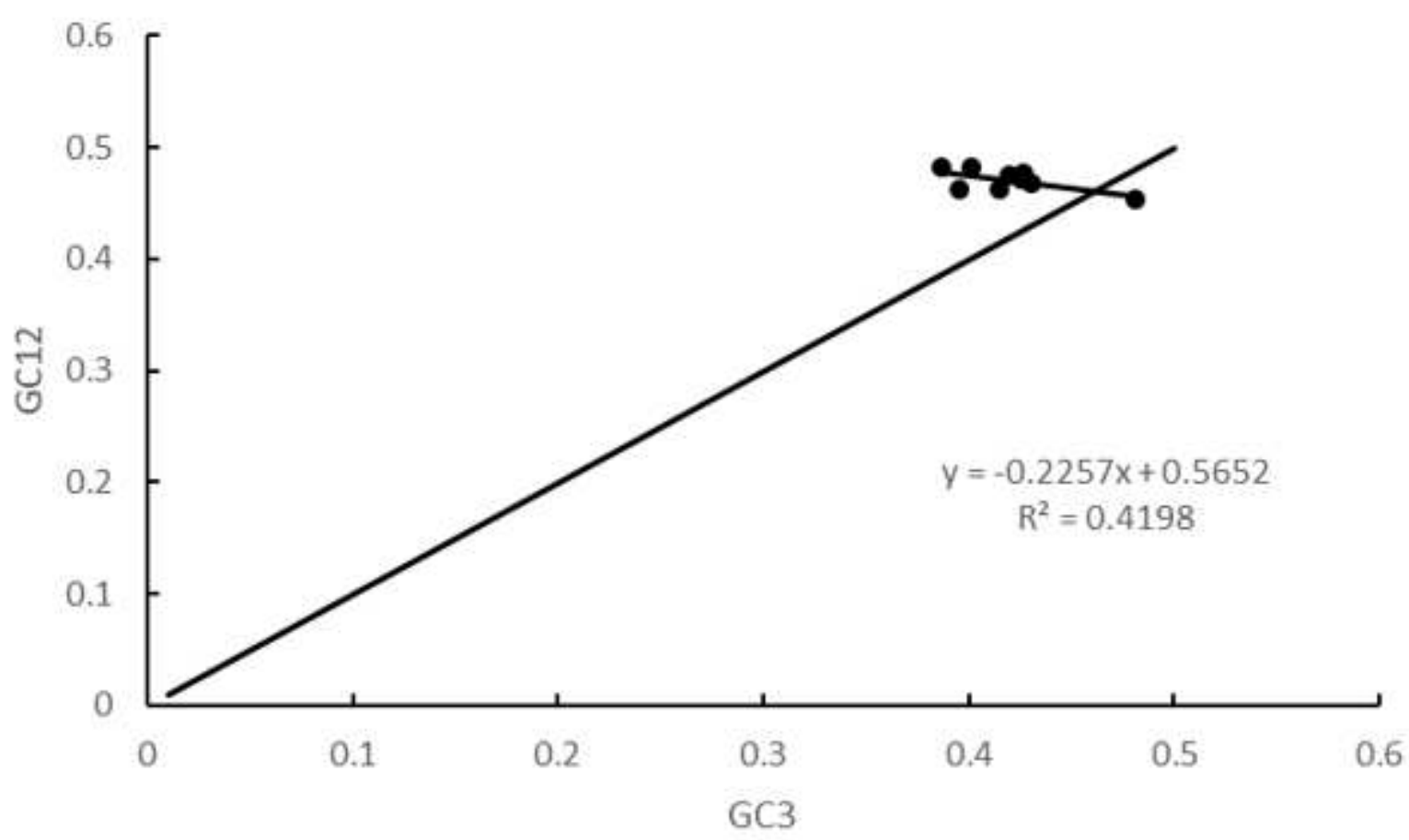

Figure 1

Neutrality plot analysis of mitochondrial genes of E. fuscoguttatus 


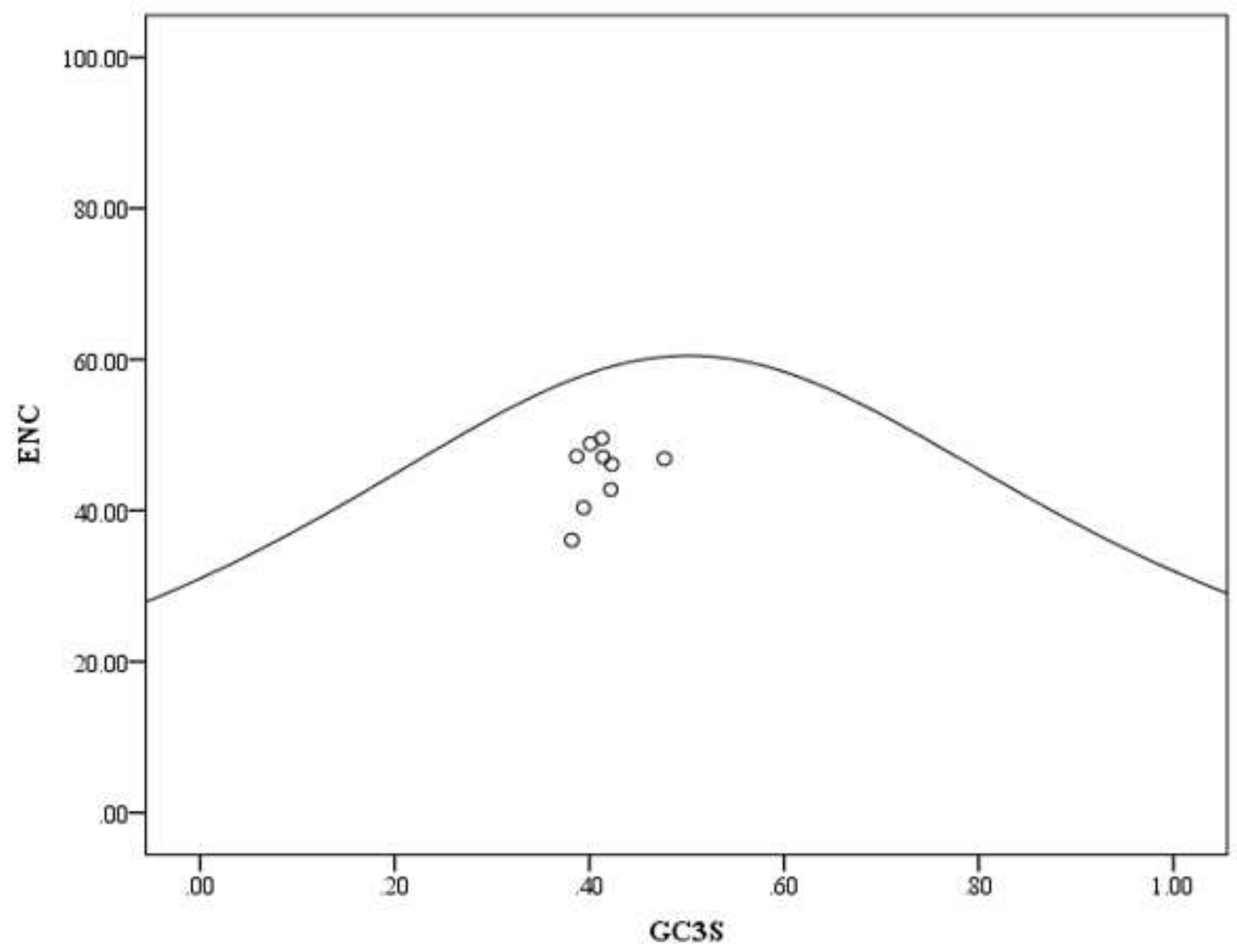

Figure 2

ENC-plot analysis of mitochondrial genes in E. fuscoguttatus 


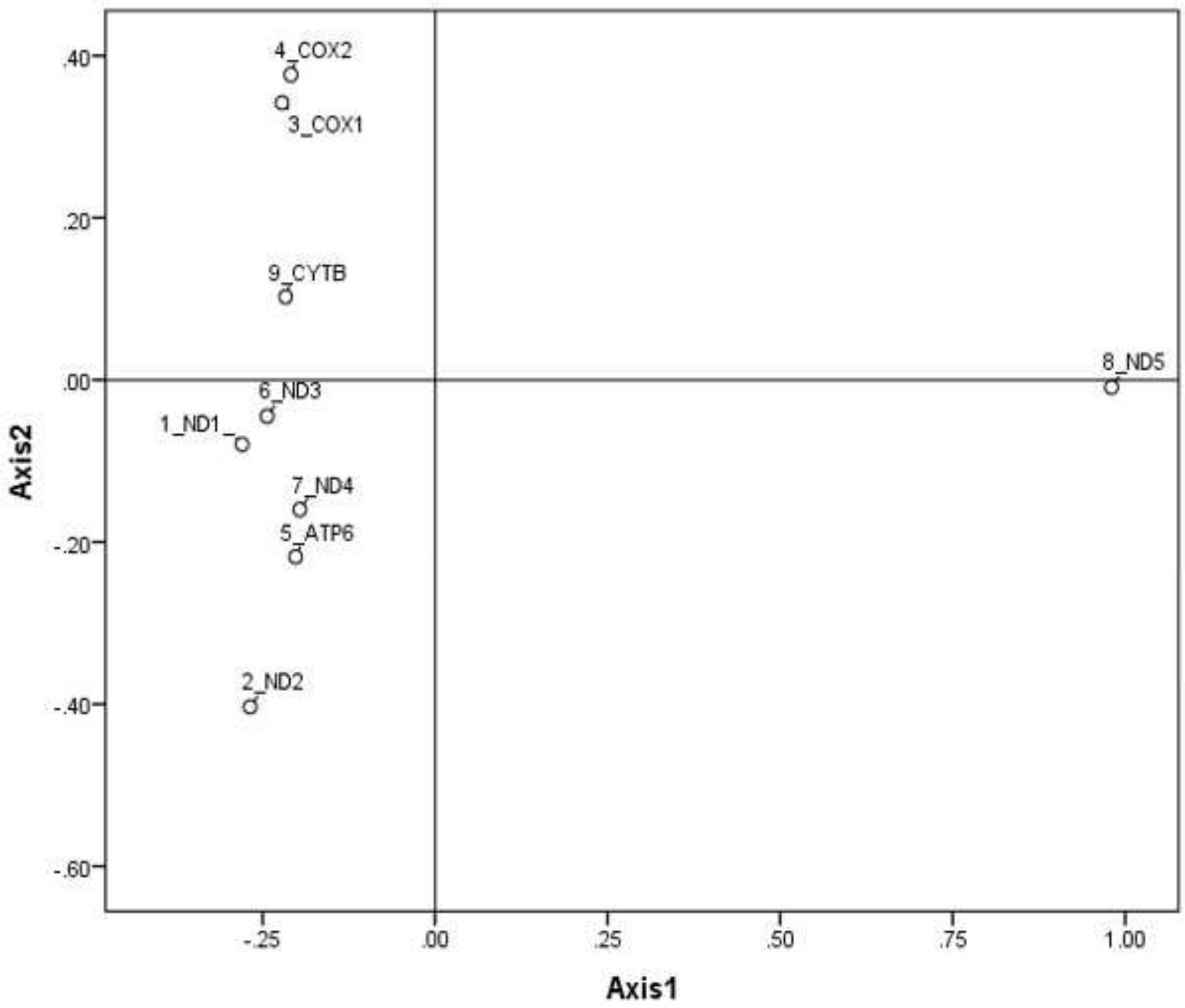

Figure 3

Corresponding analysis based on RSCU 